DOI: $10.5216 /$ racs.v4.59069

\title{
10 años de historia Mapuche: desde la ley indígena al nuevo mal-trato colonial chileno (1993-2003)
}

Filip Escudero Quiroz-Aminao ${ }^{1}$

\section{RESUMEN}

En este artículo se busca repasar los primeros diez años que vivió el Pueblo-Nación Mapuche bajo el amparo de la Ley Indígena, la Corporación Nacional de Desarrollo Indígena y como se fueron desarrollando y prolongando los problemas originados desde el Acuerdo de Nueva Imperial. En el trascurso de estos diez años dilucidaremos como las organizaciones Mapuche y el Movimiento fueron cimentando su camino hacia la autodeterminación y como el paradigma cambia radicalmente desde 1997 con los sucesos de Lumako y el ascenso de la Coordinadora Arauko-Malleko de cara al siglo XXI, donde el recrudecimiento y la mano dura del Gobierno de turno hace aplicar una legislación creada en dictadura como la Ley Antiterrorista.

PAlABRAS Claves: Movimiento Mapuche. Reivindicación. Autodeterminación. Autonomía.

\section{0 anos da história de Mapuche: da lei indígena ao novo mal-tratamento colonial chileno (1993-2003)}

\section{RESUMO}

Este artigo procura revisar os primeiros dez anos que o Povo Mapuche viveu sob a proteção da Lei Indígena, da Corporação Nacional de Desenvolvimento Indígena e como os problemas originados do Acordo Nueva Imperial foram desenvolvidos e prolongados. Ao longo desses dez anos, vamos elucidar como as organizações Mapuche e o Movimento consolidaram seu caminho para a autodeterminação e como o paradigma muda radicalmente desde 1997 com os eventos de Lumako e com a ascensão do Coordenador Arauko-Malleko para o século 21, quando o recrudescimento e a mão forte do atual governo faz aplicar uma legislação criada na ditadura como a Lei Antiterrorista.

PAlAVRAS-CHAVE: Movimento Mapuche. Reivindicações. Autodeterminação. Autonomia.

\footnotetext{
1 *Estudiante Mapuche de Pedagogía en Historia y Ciencias Sociales, Universidad Viña del Mar, Chile. Colaborador e Investigador Proyecto Fi-UVM 2016-2017 "Violencia en la Araucanía, Movimiento Mapuche y Políticas estatales en Chile 1990-2015" dirigido por Dr. Pedro Canales Tapia. Miembro de la Asociación Indígena Witrapüran y Miembro del Grupo Peyepeyen. Viña del Mar, Valparaíso, Chile. E-mail: escudero.filip@ gmail.com.
} 


\section{Introducción}

La década de los noventa para el Movimiento Mapuche y el resto del continente significó en gran medida, un decenio cargado de convulsiones, controversia y ¿Por qué no? violencia, pero también se tradujo en "La "Década Ganada" de los Movimientos Indígenas" (Canales y Reas, 2013: 52) como sostiene la tesis de Canales compartida con varios autores referidos al concepto de "Década Ganada" (Davalos, 2005), nos explica que lo nombrado hace razón a "el periodo histórico en el cual los pueblos indígenas y sus respectivos movimientos étnicos, asumieron preponderancia y peso específico como actores sociales y políticos en el seno de los países en los cuales se desenvuelven, como pueblos colonizados" (Canales y Rea, 2013: 52).

Es esta década por excelencia la que levanta los distintos movimientos indígenas a lo larga y ancho del Abya Yala -nombre del pueblo Kuna a lo que conocemos como América Latina-. Ejemplos tenemos varios, el primero cronológicamente que podemos encontrar es el de Ecuador que en el año 1990 cansado del contexto en que se encontraba se llamó a la $\mathrm{V}^{\circ}$ Asamblea Nacional para movilizarse, para esto la Confederación de nacionalidades indígena de Ecuador (CANOAIE) busca establecer un petitorio de urgencia al gobierno ecuatoriano para ejercer presión por medio de un gran alzamiento de la población indígena que reclamaba sus derechos.

Otros son los casos de gran repercusión, como el ocurrido en México con el Ejercito Zapatista (EZLN) en la ciudad de Chiapas con el Subcomandante Marcos a la cabeza como Portavoz del movimiento de liberación nacional a comienzos de los noventa. Por ultimo está el ejemplo de Felipe Quispe en Bolivia, Dirigente político e Indigenista Aymara, fundador del Movimiento Indigenista Tupac Katari en los setenta, pasando por los Ayllus Rojos en los Ochenta y el Ejercito Tupac Katari, quien se resistió bajo la vía armada al gobierno, abogando por los derechos de los pueblos de Bolivia, pujando por la plurinacionalidad y la liberación de nacional, fundó en el año 2000 el Movimiento Indígena Pachakutik.

En la década de los noventa el Pueblo Mapuche no se escapa de esta realidad, que traía

consigo el contexto latinoamericano, pero una de las diferencias que puede presentar el Movimiento Mapuche de los demás movimientos, es que las ideas que se expresan en los noventa con sus distintos dirigentes provienen de más atrás de finales de los setenta con los Centros 
Culturales Mapuche quienes en 1979 se oponían al decreto de ley 2568 de división de comunidades, pasando a lo que Ad-Mapu entregaría al Movimiento Mapuche de aquellos años bajo el alero de la política partidista contra la dictadura de Pinochet, en la década de los ochenta como bien plantea José Bengoa es una donde “(...) comenzó un lento y silencioso proceso de organización indígena. (...), las organizaciones indígenas fueron adquiriendo crecientemente una “conciencia étnica” (...)” (Bengoa, 2016: 28). El caso Mapuche de toma de conciencia étnica se centró principalmente en retomar la tradición que con el pasar de los años fue negada o escondida por vergüenza, es en esta década y con mayores luces en los noventa como reaparece la figura del Longko, Machi, Werken, por nombrar algunas autoridades ancestrales Mapuche, sumado a el retorno progresivo de Nguillatun, Palin y Llellipun.

Por último, la década de los noventa comienza para Latino América con las revueltas en Ecuador en 1990, seguido de lo que Bengoa considera el "punto más alto y expresivo en el alzamiento del Ejercito Zapatista de Liberación Nacional (EZLN) en Chiapas el primero de enero de 1994. (...), la emergencia indígena ha ocurrido en casi todos los países de América Latina." (Bengoa, 2016: 29).

En 1989, Chile el Movimiento Mapuche hace las primeras muestras de organización en este caso para la vuelta a la democracia, el Acuerdo de Nueva Imperial, fue uno de los primeros hechos que le dio visibilidad al Movimiento Mapuche en la entrada a la década de los noventa, en pro de sus derechos y demandas como Pueblo, es por ellos que Canales, Escudero y Urrutia, nos plantean lo siguiente: “El movimiento mapuche apoyó la vuelta a la democracia en 1989, no obstante, rápidamente se fueron rompiendo las confianzas y el pacto de Nueva Imperial -entre el nuevo gobierno y la dirigencia mapuche- se volvió obsoleto (Canales et al 2019: 227).

El Acuerdo de Nueva Imperial se volvió obsoleto con el pasar de los años y la credibilidad que expresó alguna vez el gobierno en el Movimiento Mapuche se agotó, es por esto que el demandante e impaciente Movimiento Mapuche se termina por levantar en contra de las pretensiones paternalistas del Estado, entre 1991 y 1992 se registra el primer descontento contra el Estado y sus promesas, una organización Mapuche llamada Aukiñ Wallmapu Ngulam establece la Comisión Quinientos Años de Resistencia contra lo que se vivía en el momento como era el Quinto Centenario del viaje de Colon. Cabe destacar también que en ese mismo programa se establece crear símbolos propios para el Movimiento Mapuche, es por ello que 
dentro de este programa de rechazo se crea la nueva bandera para el Movimiento Mapuche en los inicios de los noventa.

(...), la Comisión prometió repudiar las celebraciones triunfalistas del descubrimiento de América, subrayando que aquel episodio histórico fue una "guerra de ocupación" hispana resistida por la "nación mapuche" (PAIRICAN, 2016, p. 72).

El Quinto Centenario, el acuerdo de Nueva Imperial y lo desgastada que estaban las relaciones Pueblo Mapuche y el Estado chileno, traería consigo un clima de incertidumbre, las ocupaciones simbólicas de territorio por parte del Aukiñ Wallmapu Ngulam, hacían crecer el distanciamiento entre ambas partes, lo lento que se estaba tornando la nueva Ley Indígena, nos ayuda a entender porque el descontento Mapuche con la administración Aylwin, todo esto se traduce claramente a una derrota para el Estado y su política conciliadora, mientras que el Weche Movimiento Mapuche estaba encontrando una maduración política, que se reforzaría en los siguientes años. De acuerdo con la idea de Pairican la reemergencia indígena vivida por el Pueblo Mapuche y su Movimiento, ya se encontraba fuertemente ligada a reconocer una identidad indígena y mirar hacia la autodeterminación y el bien común de su gente:

(...), la derrota del Acuerdo de Nueva Imperial; la maduración ideológica (...) del mundo mapuche politizado, y también, un contexto latinoamericano que vio una reemergencia de la cuestión indígena, crearon un contexto sociopolítico favorable para que los planteamientos más radicales del pueblo mapuche fueran recibidos positivamente por su gente (PAIRICAN, 2016, p. 71).

Los primeros cinco años de la década de los noventa, sin duda fueron de más a menos en cuanto a las relaciones entre el Estado y el Pueblo Mapuche, a raíz del escaso compromiso que existió por parte del Ex-Presidente Aylwin, acto seguido al descontento general que se propició en 1992, debemos sumar los sinsabores que dejó la nueva legislación indígena prometida en 1989, en octubre de 1993 sale a la luz pública la Ley № 19.253 o conocida como Ley Indígena, por una parte el Estado orgulloso por sus cuatro años de discusión y por el otro el Pueblo Mapuche que se queda en la misma situación en la que se encontraba en 1989, sin reconocimiento constitucional, relegado como etnia, sin reconstrucción histórica de su territorio, no existe autodeterminación, por ende había que hacerse la idea de la inexistencia como Pueblo libre determinado en respuesta a este último punto se les cambia el rotulo de reducción y se suaviza el lenguaje racista colonialista al de comunidad. 
Para la derecha, los conceptos de pueblo o autonomía eran impensables, ya que, (...), propiciaban la división del país. Tampoco fue ratificado el reconocimiento constitucional, ni la protección a sus derechos económicos y sociales. (...). "Fue un duro revés en la política indígena del Gobierno del presidente Aylwin y de la transición a la democracia rememoró años después el entonces director del CEPI, José Bengoa (PAIRICAN, 2016, p. 72).

La Ley Indígena es otro fracaso de la administración de Patricio Aylwin, primero por el gran revuelo que tuvo a nivel nacional, donde se entendía que por fin se terminaría el "problema indígena", segundo la gran cantidad de consultas a comunidades y a los distintos Pueblos que cruzan el "territorio chileno", tercero el gran debate existente en el congreso, sumado a las molestias de la derecha criolla que enciende las alarmas y pone en tela de juicio el quiebre de la "soberanía nacional", considerando todo lo anterior y los años que demoro la Ley en ser publicada, hicieron de una y otra manera que la administración presidencial de Aylwin perdiera credibilidad en la población Mapuche, es por ellos y como lo plantean Correa y Mella:

Respecto a la Ley Indígena, se realizaron más de 900 congresos a fin de discutir el nuevo cuerpo legal, reafirmando las demandas señaladas precedentemente. Sin embargo, dicha Ley, signada con el $\mathrm{N}^{\circ} 19.253$, sufrirá importantes modificaciones a la propuesta original, las que debilitaron notablemente sus contenidos. No consagró el reconocimiento constitucional a los pueblos indígenas así como tampoco ratificó el Convenio $\mathrm{N}^{\circ} 169$ de la Organización Internacional del Trabajo. Junto a ello, la ley no reconoció jurídicamente el carácter de "pueblos" a los pueblos originarios, sino que se refiere a "etnias", lo que las propias organizaciones planteen que con ello se desconoce su trayectoria histórica, su legado cultural y la reclamación por sus territorios anteriores a la conformación de los Estados Nacionales. (...) (CORREA y MELLA, 2010, p. 203204).

Como bien sintetizan la idea los autores, nos podemos dar cuenta como el proyecto de Ley fue cercenado, que toda la base de las promesas que surgieron en 1989 por medio del Acuerdo de Nueva Imperial fueron incumplidas, en palabras de Pedro Canales Tapia, el autor nos hace referencia que la promulgación de la Ley no es otra cosa que una desobediencia política a la demandas del Pueblo Mapuche, que a su vez sigue con las mismas lógicas decimonónicas del siglo XIX, sumado al racismo exacerbado de seguir mirando a los pueblos como salvajes ajenos a las ideas de desarrollo, con la Ley Indígena se sigue perpetuando una mirada racista, desinteresada y vertical con los Pueblos afectados por la legislación wingka: 
La ley promulgada no dejó de ser la expresión "desarrollista" de un conglomerado de legisladores que, desoyendo la voz de las bases, mantuvo el infranqueable acervo liberal decimonónico y la marca proteccionista de este siglo. No pudieron extirpar de sus raciocinios la idea de indígenas incapaces, lejanos al desarrollo e ineficientes. De esta forma los vicios del pasado no fueron erradicados, inaugurando una historia con claros indicios de permanencia intolerante (CANALES, 1998, p. 50).

El reconocimiento que tuvo la Ley Indígena fue precario a raíz de no reconocer a sus pueblos como tales, sino entregando alternativas que acrecientan la brecha vertical que existe hasta nuestros días entre el Estado y el Pueblo Mapuche, siguiendo con lo que plantea Canales Tapia "El legislador no incorporó al texto final el reconocimiento constitucional de los Pueblos Indígenas, posibilitando la legalización de la comunidad, (...). Asimismo, las autoridades étnicas no fueron legitimadas por ley, ni menos la posibilidad de que resolvieran internamente querellas y peticiones" (Canales, 1998: 50). La legislación no reconoce constitucionalmente a su Pueblos, por ende esta ley se graba fervientemente en el subconsciente de los otrora comuneros quienes vieron como la oportunidad de ser escuchados se les esfuma delante de sus ojos, esta nefasta legislación wingka traería consecuencias para los años siguientes, donde las relaciones entre el Pueblo Mapuche y el Estado chileno comienzan a caminar por distintas rutas, declarándose insostenibles en unos años más.

\section{Relaciones disimiles y la nueva intifada Mapuche}

Para los años siguientes, vuelve a triunfar la Concertación de Partidos por la Democracia en las elecciones, quien se alza como el triunfo sería el hijo del Ex-Presidente de la Republica el Demócrata Cristiano Eduardo Frei Montalva, ahora era el turno de su hijo Eduardo Frei RuizTagle, pretendía seguir innovando en políticas indígenas. En los primeros años de su administración la CONADI - Corporación Nacional de Desarrollo Indígena - funcionaba de manera regular, de a poco la CEPI deba paso a la nueva entidad estatal, es por esto que los Mapuche comenzaron a dar su uso, inscribiendo las familias y sus tierras en el fondo de tierras indígenas, para que de esta forma presentar una demanda formal y también con el apoyo de CONADI hacer crecer sus tierras y solicitar documentación certificada por el Estado y volver a los juicios por tierras usurpadas. Frente a este último apartado y el colapso que presentaba CONADI a pocos años de su creación, Pedro Canales plantea lo siguiente: “(...). CONADI no 
puede hacer más que pedir "paciencia” y "esperar" ya que no cuenta con los medios materiales ni legales para solucionar 50 conflictos por restitución de tierra usurpada a los Mapuche, (...)” (Canales, 2014: 234).

Se puede considerar que entre 1994 a 1996 el ambiente entre el Estado y el Pueblo Mapuche se mantuvo "tranquilo" en una especie de tregua una pausa, las relaciones se tornaron trizadas desde 1992 y la desconfianza creció un año después a causa de la Ley Indígena, y año tras año se fueron conflictuando aún más, el primer quiebre del gobierno de Frei hijo fue la aprobación de la hidroeléctrica Ralco en territorio Mapuche-Pewenche.

(...) la consiguiente aprobación del Proyecto Ralco en el territorio pehuenche, contraviniendo expresamente el espíritu y la letra de la Ley Indígena; y las promesas de ampliar las tierras indígenas y la ausencia de voluntad política para llevarla a la práctica...(...) (CORREA y MELLA, 2010, p. 217).

Se puede asumir que la construcción de la hidroeléctrica Ralco en territorio MapuchePewenche, es el primer gran espaldarazo del Gobierno de Frei a la política indígena que se venía desplomando desde 1992, con el despertar de la rabia Mapuche y la organización, sumado a lo que Pairican indica como Maduración Ideológica, la seguidilla de malos tratos y acuerdos que se los lleva el viento, hace que la nueva generación de organizaciones Mapuche y sus militantes se levanten en armas y se radicalicen, ante tantos atropellos. Jorge Pinto sostiene que las movilizaciones Mapuche también son provocadas por la injusticia y discriminación del Estado y Nación.

La conciencia de esas injusticias y discriminaciones son las que ponen en tela de juicio el carácter de nuestro Estado y Nación. "Si bien las actuales movilizaciones mapuche has tenido como eje articulador la tierra y el territorio, (...), esto no deja de ser una muestra parcial del conflicto Nación-Mapuche/Estado chileno. Está claro que este es el factor detonante de las actuales movilizaciones y principal argumentación de lucha mapuche (PINTO, 2015, p. 312).

La hidroeléctrica Ralco de capitales españoles, es el preludio de lo viene para finales del año 1997, el descontento es general y el gobierno a pesar de la negativa por parte de los consejeros de CONADI a la construcción de Ralco sumado el director de dicho organismo Domingo Namuncura, por parte del Presidente Frei la construcción va, independiente de la opinión del máximo organismo indígena frente al Estado de Chile, aun así la voluntad política por parte del máximo mandatario es nula en pro de buscar una solución al tema de Ralco y las 
tierras Mapuche-Pewenche. Frente a la problemática de las tierras Mapuche-Pewenche, Correa y

Mella indican que:

Lo que no se señala es que las familias pewenche desalojadas de sus tierras ancestrales tienen un estilo de vida que abarca dos espacios, la invernada, la ruka y sus espacios aledaños, huertos, cercos, en las cercanías del Bío Bío, a 600 metros de altura sobre el novel del mar, donde se viven 7 a 8 meses del año, durante el tiempo lluvioso e invierno; y la veranada, emplazada a partir de los 900 metros sobre el nivel del mar, normalmente cubierta de nieve durante los meses de invierno pero durante la primavera y el verano las familias se trasladan hacia allá para mantener y alimentar sus ganados, para recolectar "piñones", el fruto del pewén (...). La oferta de ENDESA no es otra que trasladarse a vivir todo el año al fundo El Barco, (...), se esconde, que 4 meses al año las familias estarán cubiertas por nieve, que no hay agua, que se hace imposible la cría de animales y ganados, la mantención de cultivos, (...). No cabían 4 familias y se traslada a 83 familias. Por donde se le mire significa la muerte del pueblo pehuenche (CORREA y MELLAS, 2010, p. 224-225).

Siguiendo con la tesis de los autores, según su parecer:

Para las organizaciones mapuche la aprobación de Ralco en el territorio pewenche nos fue solo la aprobación de un proyecto, con ello, en palabras de Alihue Antileo. "El gobierno ha enterrado la Ley Indígena y hoy mismo asistimos al velatorio de lo que fue la Conadi” (CORREA y MELLAS, 2010, p. 224-225).

En paralelo a lo que sucedía con Ralco, desde 1997, el Gobierno de Frei y el Movimiento Mapuche comienzan la crisis más aguda de la década, Fernando Pairican describe los primeros siete años de la década fueron claves para la toma de conciencia y sentir apego por la identidad:

En los primeros siete años de retorno a la democracia, las expresiones políticas del pueblo mapuche lograron sembrar una ideología que provocó una conciencia identitaria, que se (re)fortaleció ante el despliegue del neoliberalismo corregido por las viejas fronteras de Arauco y La Araucanía. Crucial en este proceso fue la construcción de la represa hidroeléctrica Ralco en las impenetrables selvas de Alto Bío Bío. Era, además, intervenir el legendario y poderoso río, aquel que había sido el símbolo de la división entre lo mapuche y lo chileno. (...) (PAIRICAN, 2016, p. 91).

Para José Bengoa la década de los noventa en especial desde el año 1997 en adelante nos dice que los niveles de violencia van en aumento, principalmente por el contexto que vive la región de una transición democrática, sus habitantes indígenas y los movimientos que estaban naciendo de las revueltas como es el caso de Ecuador y Bolivia, y las revueltas indígena campesina en México. El caso de Chile no escapa a las tres realidades descritas, es a finales de 
1997 cuando el conflicto llega a su punto más álgido y la conflictividad entre el Pueblo Mapuche y el Estado corría por los pasajes más oscuros de los últimos años. El autor indica que:

En Chile, por su parte, el nivel de conflictividad entre los Mapuche y el Estado ha aumentado fuertemente en los años recientes como consecuencia de la "emergencia" de la cuestión mapuche, las demandas crecientes del nuevo movimiento indígena, los cambios de paradigma que se plantean al Estado, sobre todo, la dirigencia joven y la sociedad y la renuncia de la dirigencia política chilena a abrir espacios a estas nuevas dimensiones (...) (BENGOA, 2016, p. 23).

Es así como en 1997 la situación se tensó a tal punto que ya el daño provocado por la indiferencia del Estado era irreparable, es por ello que en el mes de octubre de dicho año, miembros de las comunidades Pichiloncoyan y Pilinmapu hacen ingreso al fundo Pidenco, reclamando tierras ancestrales o tierras antiguas, donde a las horas son desalojados por carabineros, este hecho en particular inaugura una nueva forma de recuperar tierras, en este caso a la fuerza y lo que responde a Control Territorial, término acuñado por la Coordinadora AraukoMalleko, a la postre se declararía el quiebre total de las relaciones Pueblo-Nación Mapuche/Estado chileno y se abriría un nuevo foco a la Lucha Mapuche como es frenar la maquina neoliberal y las empresas forestales quienes se hacen de grandes extensiones de tierra y cercan entre pinos y eucalipto las comunidades Mapuche de la provincia de Malleco.

Todo esto trae consigo sequias, problemas hidricos y suelos erosionados e improductivos, podemos hacer mención que las comunidades se enfrentan duramente a la extrema pobreza. Frente a este hecho en particular Correa y Mella dicen lo siguiente:

En el ambiente descrito es que las comunidades mapuche de Lumaco comienzan a ocupar y reocupar una serie de predios de propiedad de las empresas forestales, dando el "puntapié inicial" las comunidades de Pichloncoyan y Pilinmapu, ingresando en la madrugada del 13 de octubre de 1997 al interior del fundo Pidenco, las "tierras antiguas", paralizando las faenas de la Forestal Bosques Arauco y siendo luego desalojados por carabineros previa orden del gobierno regional, brutalmente golpeados y detenidos 37 mapuche (CORREA y MELLA, 2010, p. 217-218).

Los mismo autores nos dicen que en las próximas semanas se sumarian más comunidades Mapuche a recuperar tierras ancestrales, de esta forma cambia el paradigma en la manera en que se comenzaba a recuperar territorio usurpado, con la CONADI ampliamente cuestionada, en accionar Mapuche organizado comienza a surtir efecto en las comunidades de la Provincia de Malleko, en especial la comuna de Lumako que es donde se centraría este revés que le estaría 
propinando el Movimiento Mapuche a las políticas Indígenas de Gobierno de Frei. Debemos destacar que el conflicto se traslada a los capos verdes de nuestro Wallmapu, Correa y Mella nos dicen que el Movimiento Mapuche vuelve a reivindicar territorio usurpado en la comuna de Lumako, con el pasar de los días más comunidades comienzan a movilizarse y a recuperar territorio usurpado.

(...), específicamente la comunidad de Reñico Grande, también en Lumaco, a terrenos históricamente mapuche, al fundo Reñico, ahora propiedad de las forestales Mininco y Millalemu.

Así ocurre luego con Collinque y Toledo Cheguan Antipi, Quetrahue, Huenchun Huenchuñir, Reñiko Chico, Temulemu, Pantano, Liucura, Didaico, en lo que constituye "el detonante de un ingente movimiento de recuperación de tierras que en la zona buscada ejercen soberanía sobre aproximadamente 9 mil hectáreas usurpadas. Un llamado de atención que, sin duda, no pasó inadvertido" (CORREA y MELLA, 2010: 218).

"El llamado de atención" no pasaría inadvertido, son varios los casos de Comunidades que se levantan en armas por medio del Control Territorial. Se abre una nueva página en la historia del Movimiento Mapuche, todo lo ocurrido entre octubre y noviembre alimentaria una nueva forma de hacer política dentro de las comunidades Mapuche.

\section{Se enciende los camiones, criminalización del Movimiento Mapuche o ¿vuelta a la ocupación?}

A finales de 1997 Wallmapu experimentaba un serio problema y esta es la depredación de recursos naturales de dicha zona, por dar ejemplos claros en la alta cordillera el proyecto hidroeléctrico Ralco no tenía vuelta atrás y su construcción era cosa de tiempo, por otro lado la industria papelera como es el caso de CELCO, perteneciente a Celulosa Arauco, destinaba a tirar sus desechos al mar, pero quien tenía mayor presencia en los suelos verdes de Wallmapu es la industria forestal que aportaba al ecosistema graves daños que hasta nuestros días son irreparables, es el caso de las empresas forestales Mininco y Arauco, con mayor presencia en territorio Mapuche, que en algunos casos encierra comunidades y las destina a secar sus fuentes hídricas, estropear cosechas y enfermar a comuneros y comuneras. Sin duda la industria 
extractivista en el país Mapuche solo trae pobreza y daños al ecosistema y la vida circundante a él.

El día 1 de diciembre de 1997 Lumako y Wallmapu amanecen con la sorpresa de la quema de tres camiones de transportadores de madera, pertenecientes a la empresa forestal Arauco, quien se encuentra presente en la provincia de Malleco. Este hecho en particular seria eje articulador y detonante para el acenso de la movilización Mapuche en la zona. También los sucesos de Lumako ratifican el fracaso de las políticas indígenas de los gobiernos de la concertación, las administraciones Aylwin y Frei, además cabe destacar que con este fracaso el Acuerdo de Nueva Imperial de 1989, la Ley Indígena de 1993 y CONADI son el resultado de promesas incumplidas y proyectos ralentizados y muy mal aplicados. Para José Marimán el significado que tiene la quema de camiones en Lumako:

\begin{abstract}
El fuego sobre los camiones de la Forestal Bosques Arauco, puso un epilogo momentáneo a una situación de agitación y demanda mapuche, por restitución de tierras expoliadas. Al mismo tiempo, las llamas que consumieron los camiones de la Forestal Bosques Arauco, generaron un nuevo escenario para la confrontación por restitución de tierras expoliadas a la nación mapuche. En ese nuevo escenario, por primera vez desde el fin de la dictadura, la desesperación mapuche estallo en violencia; mientras el gobierno de la Concertación por segunda vez en un año (recordar el caso Ralco), tomaba partido del lado de los intereses de los empresarios chilenos (MARIMAN, 2015, p. 338).
\end{abstract}

Los sucesos de Lumako no solo se resumen en la quema de tres camiones forestales, sino que en ello se resumen más de 100 años de abusos y atropellos wingka, Lumako es esa delgada línea que se pone fin a las relaciones y las mesas de dialogo entre Mapuche y chilenos, y es el punto de partida de las recuperaciones de tierra usurpada y la lucha frontal con los aparatos de defensa con que cuenta el Estado. Es el momento de plantear la Autodeterminación del País Mapuche. “(...) Lumaco marcó "una nueva etapa en la lucha del pueblo mapuche por la recuperación de sus tierras y sus derechos como nación”. (...), “son la culminación de un proceso y, al mismo tiempo, el inicio de una nueva etapa en nuestra lucha (...)" (Pairican, 2016: 108).

Con los sucesos de Lumako se abren varios focos de conflicto, se levantan en distintos puntos de Wallmapu comunidades a recuperar tierras, la movilización Mapuche, toma otro impulso, es el "estallido de violencia subalterna" como diría Pairican, es gracias a los sucesos de Lumako como la Coordinadora Arauko Malleko (CAM), comienza liderar las distintas ocupaciones que se traducen en Control Territorial, comienzan a pregonar en las comunidades 
Mapuche las ideas de alcanzar la autonomía por medio del control y ocupación de fundos forestales y privados, la CAM plantea como plantean los Pu Lov y Comunidades Lavkenche en resistencia "La CAM plantea en ese tiempo romper con el colonialismo." (Xipantü, 2017: 117), con Lumako el cambio de paradigma en las movilizaciones Mapuche de finales del siglo XX.

La misma historiografía Mapuche es quien se encarga de reconocer la importancia que tuvo este hecho en particular, es primera vez desde la dictadura y la implementación del DL701 que las forestales se sienten amenazadas por la avanzada Mapuche, por su parte este hecho a la CAM le sirvió como trampolín para comenzar a concientizar y levantar en Weichan a las comunidades, es el caso de las comunidades del Lleu-Leu.

Llegaron los sucesos de Lumaco en 1997 y el tema mapuche se instala en el debate nacional chileno.

La historiografía mapuche ya reconoce que este hechos bien a cambiar el paradigma del conflicto. Las empresas forestales por primera vez se sienten golpeadas y amenazadas. (...).

En ese tiempo las movilizaciones en este territorio lavkenche estaban focalizadas principalmente en torno al lago Lleu-Lleu y en Tirua Sur, también destacaban Colcuma y Las Huellas, un poco hacia el sur del lago. Más al norte en la comuna de Los Alamos se luchaba por el fundo Cuyinco, con más aislamiento por la distancia.

En torno al lago Lleu-Lleu se articuló la Coordinadora Arauco Malleco (CAM), con una estructura organizacional y liderazgos algo concentrados. (...) (XIPANTÜ, 2017, p. 115116).

Las portadas del Austral de Temuco durante el mes de diciembre nos arrojan un clima de inseguridad implantado por este sector editorial, a lo largo de toda su vida periodística se destaca por ser anti-mapuche, las portadas del 2 de diciembre de 1997 dice por ejemplo "Violenta protesta mapuche. Queman 3 camiones asalto a vehículos de forestal” (Diario Austral, 1997), en cambio para el día siguiente titula "Estrategia subversiva en Lumaco ¡Son terroristas! Ocultos tras causa mapuche" (Diario Austral, 1997) tras las legítimas demanda Mapuche se agrega un apelativo racista que a sectores empresariales, terratenientes y la política chilena, les acomoda para tratar las legítimas demandas del Movimiento Mapuche, englobando todo a acciones de sabotaje terroristas y la paranoia del entonces Diputado Alberto Espina de que grupos subversivos extranjeros estaban detrás del Movimiento Mapuche, como las FARC y ETA y las nacionales FPMR y el MIR. En los campos se instala una realidad adversa con la que vivimos 
hasta nuestros días como es la criminalización del Movimiento Mapuche y se establece en el imaginario colectivo de que son terroristas.

\section{El Fütra Malon del siglo XXI}

El año 1997 concluye con un Wallmapu convulsionado, sectores políticos, empresariales y terratenientes, para proteger sus intereses económicos hacen un llamado público para que se aplique la Ley de seguridad del Estado, el Diputado de Renovación Nacional Francisco Bayo solicita al Ministro del interior Carlos Figueroa la aplicación de la Ley Antiterrorista para lo sucedido en Lumaco (Diario Austral, 1997). Frente a la aplicación de la Ley de Seguridad al interior del Estado, los dirigentes Victor Nagil y Galvarino Reiman, en conjunto con dirigentes de la UCT y UFRO, para Nagil “(...) la aplicación de la Ley de Seguridad Interior refleja un conflicto de fondo entre el pueblo mapuche y el Estado chileno y cuestionó duramente que pueda existir imparcialidad de los Tribunales" (Diario Austral, 1997). Por su parte el dirigente de la Asociación Mapuche de Lumaco señala que: “(...) es una especulación sostener que existan personas infiltradas en las comunidades y lo que ha ocurrido sólo beneficia a la propiedad privada y al modelo económica.” (Diario Austral, 1997). El propio Reiman afirma que: (...) la propia forestal podría estar interesada en hostigar la reivindicación territorial de la comunidades haciendo parecer a los mapuches como victimarios" (Diario Austral, 1997).

El situación en la novena región estaba totalmente desalineada y sin control, las cárceles de la octava, novena y décima región se encontraban con Mapuche que fueron acusados de los distintos procesos de recuperación territorial, es por ello que entre 1998 a 2003 el desfile de imputados Mapuche fue en incremento, acusaciones por “Asociación Ilícita Terrorista”, con él, la mayoría de los militantes de la CAM y autoridades ancestrales partían derecho a las cárceles de la frontera, el proceso de reemergencia nacionalitaria Mapuche comenzó. Héctor Llaitul en sintetiza mejor este último concepto:

Un proceso nacionalitario que para los pueblos originarios (...) se expresa en una progresiva afirmación identitaria y nacional, punto de consenso asumido por las diversas organizaciones que plantean reivindicaciones históricas, lo cual nos ha permitido lograr algo fundamental para este proceso, que es posicionar a la Nación Mapuche en el ámbito internacional. Es en este contexto que la Coordinadora Arauco-Malleco (CAM) ha creído necesario asumir la bandera mapuche como elemento simbólico, sin embargo, 
sigue plateando que es el territorio la condición básica para el ejercicio de nuestros derechos políticos, sociales y culturales (LLAITUL, 2013, p. 34).

Entre 1998 y el nuevo milenio, las comunidades y el movimiento Mapuche se fueron radicalizando en pro de los ideales de la liberación nacional, a lo largo de américa latina este mismo proceso se estaba dando de forma natural, entre febrero de 1998 y agosto de 1999 la Coordinadora Arauco-Malleco inicia un levantamiento Mapuche en distintos puntos de Wallmapu, un ejemplo es lo que sucede en Traiguén con la comunidad de Temulemu, con el Ñizol Longko Pascual Pichún Paillaleo quien con las comunidades de Pantano y Didaico, retoman las recuperaciones reclamadas desde 1931 del fundo Nancahue y Santa Rosa de Colpi, para estos años se definen por parte de la CAM quienes son los enemigos del Pueblo Mapuche, José Huenchunao sostiene que son el "sistema capitalista, sus planes y sus ya materializadas inversiones, y al Estado chileno por ser un entramado del capitalismo y por generar las actuales contradicciones existentes. (...)" (Huenchunao, 2013: 29). El mismo Huenchunao define que las aristas del proyecto político de liberación nacional que sostiene la CAM y el Movimiento Mapuche son: “(...) la defensa del territorio histórico, por las reconstrucción de la autonomía y por el desarrollo de nuestro pueblo. (...)" (Huenchunao, 2016: 15-16).

En el caso de los fundos en disputa de las comunidades de Temulemu, Pantano y Didaico, contra forestal Mininco y la familia Figueroa Yavar por los fundos Santa Rosa de Colpi y Nancahue fue sin duda una de las fue una de las organizaciones por recuperación de tierra Mapuche más importante entrando el siglo XXI, las movilizaciones empezaron en abril de 1998 donde “(...), la situación territorial de la comunidad mapuche de Temulemu era similar a la parte importante de las comunidades mapuche de Malleco. Es decir, en primer término, había demandas de tierras antigua ocupación (...). En el primer caso, la referencia es al fundo Santa Rosa de Colpi y al fundo Nancahue; (...). Todo ello dio pie para la demanda territorial de las organizaciones y comunidades mapuches y a la consiguiente respuesta del Estado chileno, la criminalización del conflicto" (Correa y Vergara, 2014: 55-56).

Uno de los grandes réditos que dejo la ocupación y control territorial de tierras usurpadas, es que el gobierno se atreve a intervenir en la compra de dichas tierras para los Mapuche con el compromiso de no volver a estas prácticas, "Como resultado de esta sostenida movilización, a mediados del año 1999, las 58,4 hectáreas pertenecientes al título de merced de Antonio Ñiripil 
fueron compradas por el Estado chileno -a través de CONADI- a forestal Mininco, (...) en un valor que alcanzó a \$110.000.000 (...)” (Correa y Vergara, 2014: 58).

Domingo Namuncura en su tiempo como director de CONADI, condenó rotundamente los hechos ocurridos en Traiguén y claramente su postura es contraria a la forma en la que se quiere recuperar las tierras, por ende reiteró en varias ocasiones que "fundo tomado, fundo no comprado" (Correa y Mella, 2010: 222), y se declara en contra de las formas que las comunidades están buscando negociar por la tierras, "las comunidades mapuche ven en las ocupaciones de los predios el único camino para que sean tomadas en cuenta sus demandas territoriales" (Correa y Mella, 2010: 222).

Frente a la política de compra de tierras, Hector Llaitul Carillanca, afirma que es una "Solución Neoliberal" porque responde a la "imposición del sistema capitalista y continuidad de éste en nuestro territorio" (Llaitul, 2016: 24). Para la CAM el sistema de compra de tierras por medio de CONADI, no era la solución a las demandas autodeterministas que plantea la organización, al contrario la compra de tierras por medio de CONADI, es un movimiento del Estado que busca debilitar a la Coordinadora que en su proyecto de liberación nacional.

La violencia en los campos para el nuevo milenio vendría acompañado con un nuevo Presidente, en este caso la Concertación se repite el sillón presidencial por tercera vez, en una elección reñida logra salir vencedor Ricardo Lagos Escobar, sin duda de los gobiernos más rígidos en el trato con las comunidades indígenas, gobierno que implementó mano dura contra el imaginario colectivo implantado por la clase política chilena del "movimiento terrorista" que azotaba los campos de la vieja frontera y a los pobres agricultores y empresas forestales.

\section{La "mano dura" de Gobierno de Lagos}

Para el año 2001 el Movimiento Mapuche estaba viviendo días de enfrentamientos con Forestales y Colonos, para esto el Gobierno de Lagos bajo la idea de poner "orden" en la Araucanía limpiaría el polvo de una ley creada en dictadura como es la Ley Antiterrorista, lo curioso que esta ley no se llevó a cabo para terminar con el terrorismo, si no que para inculpar a los Mapuche y tenerlos encerrados mayor cantidad de tiempo, aislar a la CAM y provocar 
desgastes significativos en el Movimiento Mapuche y las familias de los imputados, Pedro Cayuqueo afirma que entre 2001 y 2003 son doce las querellas por "terrorismo":

\begin{abstract}
Entre los años 2001 y 2003, las querellas por "terrorismo" fueron doce y se acumularon en cuatro emblemáticos procesos. Estas se sumaron a otras 80 causas por distintas leyes penales contra un total de 209 ciudadanos mapuche. Estos cuatro procesos fueron (...) el caso Ancalaf, por "incendio terrorista" en Alto Biobío; Caso Lonkos, por "amenaza terrorista" contra un latifundista de Traiguén; Caso Poluco Pidenco, por "incendio terrorista" de predio de Forestal Mininco; y el bullado Caso CAM, por "asociación ilícita terrorista" en Temuco. Los tres primeros, precisamente los casos analizados por la Corte IDH, terminaros con los acusados tras las rejas (CAYUQUEO, 2014).
\end{abstract}

Para hacer frente a la Ley Antiterrorista el Movimiento Mapuche ve nacer en 2001 la mítica figura guerrera que renacía de desde el imaginario de la Guerra de Arauco, aparece el Weychafe, que abre una nueva vertiente en la contra-violencia Mapuche como sostendría Tito Tricot, el Estado estaba dando duros golpes al Movimiento y en especial a la CAM, sin duda la aparición del Weychafe le da un nuevo aire a las reivindicaciones de la Coordinadora desde 2001, el aparato represivo Estatal Legislaba contra las reivindicaciones y la autodeterminación Mapuche, ya que “(...) la represión que desde 2001 comienza a ejercerse desde el Estado como política, va forzando la necesidad de cerrar los espacios de la organización (...), es desde el 2001 que comienza una suerte de violencia política mucho más planificada y racional” (Tricot, 2017: 73).

Un segundo golpe que da el Gobierno de Lagos es la ratificación de la Hidroeléctrica Ralco en Territorio Mapuche-Pewenche, las sentidas palabras de la principal dirigenta Nicolasa Quintremán muestra la triste realidad que cruzan los Pewenche olvidados y pauperizados por los gobiernos de la Concertación, para 2001 la fallecida dirigenta Mapuche Pewenche vaticinaba lo siguiente: “(...) Pasando Ralco, (...), terminaremos nosotros, puh. Termina pehuenche y terminará de todo también. Porque sin pehuenche no va a estar firma el mundo (...)" (Opaso, 2012: 275). Entre el Estado y la empresa trasnacional ENDESA interactuaron para inaugurar el megaproyecto Ralco y pasar por encima de los derechos territoriales Mapuche-Pewenche inundando 3500 hectáreas en el Alto Bio Bío. 


\section{5 “Operación Paciencia” en acción}

Para el año 2002 el Gobierno de Lagos con la Ley Antiterrorista inaugurada, el movimiento Mapuche recibe otro golpe, de en este caso dirigido a los militantes de la CAM, los cuales perseguidos por el Estado y el general Bernales; la inteligencia chilena comienza a perseguir a los miembros de la Coordinadora, la Operación Paciencia buscó la desarticulación de la CAM, Pairican afirma que:

La operación Paciencia investigó al movimiento autodeterminista en su plenitud, pero se focalizó en la CAM, a esa altura consignada por la Dirección de Seguridad Pública (DISPI) (...), como una organización "insurreccional" que buscaba "incentivar un alzamiento indígena". (...), la CAM había cambiado su estructura política, estableciendo un "dirección colectiva" en la cual se decidían "las estrategias de lucha en el plano operativo y político" (PAIRICAN, 2016, p. 52-53).

La CAM se encontraba en su mayor despliegue político, para el Estado y la Operación Paciencia la CAM representaba un "riesgo social" sostiene Pairican, para los primeros años del siglo XXI los conflictos en los campo seguían intensificándose, un grupo de colonos crea el Comando Hernán Trizano, para hacer frente al levantamiento indígena en Wallmapu, ya que los colonos no creían en lo que se desarrollaba con la Operación Paciencia, como dice Cayuqueo, la "denominada "Operación Paciencia” montada por el (...) subsecretario del Interior, Jorge Correa Sutil y dirigida contra la cúpula de la Coordinadora Arauco-Malleco, CAM" (Cayuqueo, 2014).

Sin duda el primer ministro del interior de la gestión Lagos Jorge Correa Sutil, celebraba por los réditos que entregaba la Operación Paciencia. Mientras que los líderes de la CAM Llaitul, Huenchunao y Llanquileo, se encontraban presos o en la clandestinidad, desconectados de sus familias y las reivindicaciones en el campo. Se hablaba de que la Coordinadora Arauco-Malleco estaba desarticulada.

Frente a la escalada de la violencia en los campos de Wallmapu y como sostiene Pairican los colonos se organizan para hacer frente a los Mapuche por sus propios medios,

Los agricultores desempolvaron a un antiguo alférez de la vieja frontera considerado el primer policía de Chile. Nacía el Comando Hernán Trizano, que prometió "empezar represalias contra los señores indígenas, en defensa de los agricultores, las forestales e hidroeléctricas" (...). Mientras que el Ministro del Interior de aquel entonces, José Migue Insulza, señalaba que todos los días trabaja para que no hubiera muertos. No lo consiguió (PAIRICAN, 2016, p. 53). 


\section{Alex Lemün, el primer asesinado}

Mientras se desarrollaba la Operación Paciencia en noviembre de 2002, la CAM experimentaba una primera pausa en las reivindicaciones territoriales por el sistema de inteligencia librado por el Estado, es por esto, que muchos de sus dirigentes y militantes debían alejarse del Weychan y de sus familias, enfrentándose a la clandestinidad, pasar desapercibido e incomunicado por el rastreo de celulares y transitar de comunidad en comunidad hasta que dejaran de ser perseguidos o lo contrario capturados.

Las comunidades de Ercilla se encontraban para noviembre de 2002 librando su proceso de recuperación de tierras ancestrales, cerca de 40 Mapuche pertenecientes a la Comunidad Montitui Mapu de Ercilla hacen ingreso al fundo Santa Alicia de propiedad de forestal Mininco, el día 7 de noviembre efectivos de carabineros proceden a dispersar a los Mapuche que se encontraban ocupado simbólicamente el territorio y buscando madera para prender salamandras y cocinas, de esa forma poder sobrevivir y alimentarse. El mayor de carabineros Marco Aurelio Treuer Heysen en el contexto de dispersión donde los demás efectivos lanzan bombas lacrimógenas y munición de goma antidisturbios, procede a disparar su arma de servicio resultando herido el joven de 17 años Edmundo Alex Lemün Saavedra de un tiro en la frente, el Weychafe falleció el 12 de noviembre de 2002 en la clínica alemana de Temuco, tras 5 días agonizando. Entre 2002 a 2018 se abre un proceso difícil de describir como es la muerte de comuneros Mapuche por la defensa y recuperación de territorio ancestral por causa de bala policial.

El 7 de noviembre del 2002, Marco Aurelio Treuer disparó su armamento antimotín contra un grupo de comuneros que ejercía el control territorial en el fundo Santa Alicia de forestal Mininco, impactando en el cráneo al joven de 17 años Edmundo Alex Lemün Saavedra, quien murió cinco días después. Nacía -tristemente- lo que José Llanquileo, werken de la CAM, llamó en su eluwün como "el primer mártir de este nuevo proceso de lucha" (PAIRICAN, 2016, p 53).

Con la muerte de Alex Lemün la violencia en los campos se desparrama y son más las comunidades que empiezan a enfrentarse cara a cara con carabineros, es por esto que puntualizaba José Llanquilef werken de la CAM que "el que presagiaba el inicio de un "levantamiento del pueblo mapuche" (Pairican, 2016: 53), mientras que José Huenchunao en 
clandestinidad dice que "Si muere un mapuche creo que la gente se levantara con mayor fuerza" (Pairican, 2016: 53).

La familia de Alex Lemün hasta nuestros días pide justicia por el cobarde asesinato de su hijo, por parte de los tribunales de justicia militar en los siguientes años solo fue inculpado por el delito de "Violencia innecesaria con resultado de muerte, en libre plática, por lo cual se le fijó una fianza. Sin embargo, en septiembre de 2003 se revocó su procesamiento por "falta de méritos". El caso fue archivado en la fiscalía militar en 2004 y en 2005 la Corte Marcial confirmo su sobreseimiento. Para el 28 de septiembre de 2018 la Fiscalía de La Araucanía presentó cargos contra Treuer (Eldesconcierto, 2018).

Esta fue la forma en que el Gobierno de Lagos acogió el concepto de "Nuevo Trato" o como consignamos en esta investigación "Nuevo Mal-Trato", porque el abuso de la mano dura por parte del Estado y la promulgación de la Ley Antiterrorista, la Operación Paciencia, ratificación de Ralco y el asesinato de Alex Lemün, nos indica que claramente una relación de intolerancia y al igual que sus predecesores solo ven a los Mapuche como un Pueblo carente de derechos y que sus derechos constitucionales no tienen espacio en el gobierno empresarial y neoliberal de Lagos.

La primera mitad de la gestión Lagos (2000-2003) es sin lugar a dudas la ratificación del modelo extractivista-neoliberal en la región, las políticas indígenas del "Nuevo Trato" retroceden y responden exclusivamente a represión desmesurada que terminó con la Muerte del comunero Alex Lemun, esta comisión de Verdad Histórica y Nuevo Trato se comenzó a construir en el año 2001 con intelectuales, historiadores, dirigentes Mapuche (Algunas organizaciones como la CAM se restó de este proceso), la iglesia y el sector empresarial, para el año 2003 con un Gobierno cuestionado por el modo y la forma en que trataba a las comunidades Mapuche, sale a la luz el resultado lo que se supone sería "Un Nuevo Trato entre el Estado, los pueblos indígenas y la sociedad chilena toda" (Pairican y Álvarez, 2011: 77).

El día 28 de octubre de 2003 llega el día de conocer el resultado final de la Comisión de Verdad Histórica y Nuevo Trato, según Pairican y Álvares “(...) su contenido significó para el pueblo mapuche el reconocimiento de una historia de frustraciones y desarraigos. Sin embargo, no se pronunció sobre las complejidades del conflicto mapuche actual" (Pairican y Álvarez, 2011: 77). Tres años de trabajo se redujeron a una eterna promesa que no se cumplió, entre el 
Acuerdo de Nueva Imperial y La Comisión de Verdad Histórica y Nuevo Trato pasaron cerca de 14 años en que los avances en las políticas indígenas de la Concertación fueron mínimas, se sigue creyendo en el rol paternalista que debe tener el Estado con sus Pueblos Indígenas, viendo en ellos la incapacidad de organización. Mientras que en los mismos 14 años los avances en el Movimiento Mapuche y sus Organizaciones en pro de la Autodeterminación y los derechos colectivos, avanzaron de manera considerable, desde ocupaciones simbólicas de territorio a control territorial, el crecimiento político del Movimiento Mapuche fue sorprendente.

\section{Conclusión}

Las Administraciones de Aylwin, Frei y Lagos, fueron de más a menos con el paso de los 14 años que se estudiaron en esta investigación, es por ello que pasamos de las mesas de dialogo de Aylwin a la "neutralidad" o nulidad de cómo enfrentar el levantamiento indígena de Frei, a la mano dura y desconsiderada de Lagos, con promulgaciones de Leyes que no combaten el terrorismo, si no que se dictaron para encarcelar a quienes luchan por su derecho a libredeterminarse. Sumado a la guerra sucia que instala en los campos con la Operación Paciencia, sin duda lo más cercano a una dictadura fue el primer gobierno de siglo XXI, el espionaje y persecución política de líderes de la CAM, Aukiñ Wallmapu Ngulam y autoridades ancestrales con la Operación Paciencia, además de los largos juicios y testigos sin rostro para incriminar a los Mapuche perseguidos, nos demuestran la inoperancia que existía en la clase política para sostener el "Conflicto Mapuche", dentro de esta misma inoperancia, pudimos vislumbrar la militarización de Wallmapu y como las Fuerzas Especiales de carabineros y GOPE, acorralar y combaten contra comuneros y comuneras hasta el punto de lamentar muertes y una gran cantidad de lesionados entre ellos, niños y ancianos. Muertes como la de Alex Lemun quien marcaría un antes y un después en la "Cuestión Mapuche", y que en los próximos años lo acompañaran Matías Catrileo, Jaime Mendoza Collio, Rodrigo Melinao y Camilo Catrillanca, 16 años de Mapuche Asesinados por bala policial, vidas interrumpidas, hostigamiento y fin a la infancia de muchos niños y niñas Mapuche todo por el desinterés del Estado chileno por hacerse cargo de sus atropellos centenarios.

R. Articul.const.saber, 2019, v.4: e59069 


\section{Bibliografía}

Bengoa, J. La emergencia indígena en America Latina. Santiago de Chile: Fondo de Cultura Económica, 2016.

Canales, P. (Marzo-Abril de 1998). Una legislacion "winka" para los Mapuches. Revista Mensaje, 47(467), 49-51.

Canales, P. Tierra e Historia Estudios y controversias acerca de la historia del Pueblo Mapuche en Chile, 1950-2010. La Serena: Editorial Universidad de La Serena, 2014.

Canales, P., \& Rea, C. Claro de Luz Descolonización e "Intelectualidades Indigenas" en Abya Yala, siglos XX-XXI. Santiago de Chile: Ediciones IDEA-USACH, 2013.

Canales, P., Escudero, F., \& Urrutia, M. J. (Mayo de 2019). Violencia y Teoría. Diálogos pendientes en contexto colonial del Pueblo Mapuche. Revista Izquierdas, 46, 218-234.

Cayuqueo, P. (07 de Agosto de 2014). The Clinic. Recuperado el 14 de Abril de 2019, de theclinic.cl: https://www.theclinic.cl/2014/08/07/las-culpas-de-ricardo-lagos/.

Correa, M., \& Mella, E. La razones del Illkun/enojo. Memoria, despojo y criminalización en el territorio mapuche de Malleco. Santiago de Chile: LOM Ediciones/Observatorio de Derechos de los Pueblos Indígenas, 2010.

Correa, M., \& Vergara, J. Las Tierras de la ira. Los conflictos entre mapuches, empresas forestales y Estado. El caso de la comunidad de Temulemu (Traiguén). Santiago de Chile: Ediciones el Desconcierto, 2014.

Desconcierto, e. (11 de Agosto de 2018). elDesconcierto.cl. Recuperado el 14 de Abril de 2019, de Mayor (r) de Carabineros será formalizado por muerte de Alex Lemún: https://www.eldesconcierto.cl/2018/08/11/mayor-r-de-carabineros-sera-formalizado-por-muertede-alex-lemun/

Dávalos, P. Pueblos indígenas, estado y democracia. Argentina. CLACSO, 2005.

Huenchunao, J. Resistencia y reconstrucción del pueblo-nación mapuche. Santiago de Chile: Editorial Aún Creemos en los Sueños, 2013.

Huenchunao, J. La lucha por territorio y autonomía. Santiago : Editorial Aún Creemos en los Sueños, 2016.

Llaitul, H. Lucha Mapuche: una continuidad centenaria. Santiago de Chile: Aún Creemos en los sueños, 2013.

Llaitul, H.¿Compra-venta, expropiación o control territorial? Santiago de Chile: Editorial Aún Creemos en los Sueños, 2016.

Opaso, C. BioBío Rebelde: De Ranquil a Ralco. Santiago de Chile: CEIBO Ediciones, 2012. 
Pairican, F. Malon La Rebelión del Movimiento Mapuche 1990-2013. Santiago de Chile: Pehuen Editores, 2016.

Pairican, F. Rutas mapuche hacia la autodeterminación. Santiago de Chile: Editorial Aún Creemos en los Sueños, 2016.

Pairican, F., \& Alvarez, R. La Nueva Guerra de Arauco: La Coordinadora Arauco Malleco en el Chile de la Concertación de Partidos por la Democracia (1997- 2009). Revista Izquierdas, Agosto de 2011, p. 66-84.

Pinto, J. Conflictos étnicos, sociales y económicos: Arucanía 1900-2014. Santiago de Chile: Pehuén Editores, 2015.

Pinto, J. La formación del Estado, la nación y el pueblo mapuche de la inclusión a la exclusión. Temuco: Ediones Universidad de la Frontera, 2015.

Tricot, T. Aukan Violencia histórica chilena y resistencia Mapuche. Santiago de Chile: CEIBO Ediciones, 2017.

¡Xipamün Pu Ülka!. La usurpación forestal del Lavkenmapu y el proceso actual de recuperación. Santiago de Chile: Libros del Perro Negro, 2017.

Submetido em 17 de junho de 2019.

Aceito em 05 de agosto de 2019.

Publicado em 06 de agosto de 2019.

R. Articul.const.saber, 2019, v.4: e59069 